Journal of Agricultural Sciences
(Tarim Bilimieri Dergisi)

\title{
Effects of Two Different Isolates of Entomopathogen Fungus, Beauveria bassiana (Balsamo) Vuillemin on Myzus persicae Sulzer (Hemiptera: Aphididae)
}

\author{
Gizem BERBER ${ }^{a}$ iD, Ali Kemal BİRGÜCÜ a*

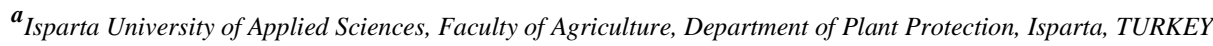 \\ ARTICLE INFO \\ Research Article \\ Corresponding Author: Ali Kemal BİRGÜCÜ, E-mail: alibirgucu@isparta.edu.tr \\ Received: 20 November 2020 / Revised: 09 February 2021 / Accepted: 10 February 2021 / Online: 20 January 2022
}

\section{ABSTRACT}

The study aimed to determine the effectivity of LD.2016 and M6-4 isolates of entomopathogen Beauveria bassiana on Myzus persicae Sulzer (Hemiptera: Aphididae). In this context, the doses of $10^{6}, 10^{7}$ and $10^{8}$ conidia $\mathrm{mL}^{-1}$ for isolates were used. Experiments for each dose and a control group were set up to be 50 repeats. As a result of the analysis, the $r_{m}$ values of the individuals exposed to $10^{6}, 10^{7}$ and $10^{8}$ conidia $\mathrm{mL}^{-1}$ doses were calculated as $0.340,0.352$ and 0.337 females/female/day, respectively for the LD.2016 isolate, and $0.292,0.263$ and 0.268 females/female/day, respectively for the M6-4 isolate. The value was 0.280 females/female/day for the control group. By increased dose, the values of $1_{\mathrm{x}}$ and $\mathrm{m}_{\mathrm{x}}$ parameters were decreased, too. Besides, the Weibull and Enkegaard models were applied on the $l_{x}$ and $m_{x}$ values of the populations exposed to entomopathogen isolates. Consequently, it is thought that the isolates of entomopathogen B. bassiana, less harmful to humans and the environment, can be used as a biological control agent in an integrated pest management program for the controlling of the pest.

Keywords: Pepper, Biological control, Integrated pest management, Aphid, Weibull

(C) Ankara University, Faculty of Agriculture

\section{Introduction}

The green peach aphid, Myzus persicae (Sulzer 1776) (Hemiptera: Aphididae), which is a polyphagous insect pest, cause damage on different plants in Turkey and can continue to do reproduce, and damage year-round under favorable conditions (Velioğlu \& Toros 2002). Individuals of $M$. persicae become harmful by sucking plant saps and secrete toxic substances into the plant during the absorption. They also cause fumagine (dark-colored sooty mold) by secreting honeydew. Another form of their damage is also by transporting plant viruses. In addition, $M$. persicae is a hard insect pest to control by dint of having wide host range, multivoltine feature and short development time (Özçelik et al. 2013).

As with many insect pests, chemical pesticides are used in the management of $M$. persicae, too. Due to chemical substances have residual risks on agricultural products, possibility of adverse impact on the environment and human health and forming resistance in pests, there has been an orientation towards biological control, which is an alternative control method (Erdoğan 2015). Considering the risks of chemical control to the environment and human, biological control is one of the most reliable methods. Many biological control agents have been studied on the controlling of M. persicae up to the present (Özçelik et al. 2013, Andorno \& López 2014, Khatri et al. 2017, Birgücü et al. 2018).

Many pathogenic organisms attack insect pests, and cause diseases upon entering their body. The use of these pathogenic organisms against insect pests for the controlling them is called microbial control. The most appropriate use of microorganis ms is to create cultures in artificial media, and then to infect them sobersidedly to environment in a suitable time (Çelebi 2012). Since entomopathogenic fungi enter directly from the insect cuticle, they do not need to be ingested by the pest and taken into the body. Therefore, entomopathogenic fungi play an important role in the management of insects whose food source is plant sap. Since about 1900s, entomopathogenic fungi have been used as biological agent (Sevim et al. 2015).

At least 700 entomopathogenic fungi species belonging to 90 genera, known were identified. In many parts of world, fungal species similar to Beauveria bassiana (Bals.) Vuill., Metarhizium anisopliae (Metsch.) Sorok., Isaria fumosorosea (=Paecilomyces fumosoroseus) Wize and Lecanicillium lecanii (Zimm.) Zare \& Gams against insect pests are developed for commercial purpose (Rath 2000). Entomopathogenic fungi have many remarkable benefits such as not being toxic to mammals, creating resistance against pests, providing long-term controlling against pests in nature, being effective in all stages of the insect, being able to be applied with most insecticides, being cheap and easy to apply (Sevim et al. 2015). It was determined that B. bassiana and M. anisophile isolates, which were commercially produced in the management of herbivore 
insects, have no risk against bees and are applicable as biological control agents (Sevim et al. 2015, Uzuner et al. 2017). In studies on entomopathogenic fungi, it was reported that their effects increase in direct proportion with relative humidity level (Demirci et al. 2011). It is stated that, from the developed pesticides, Lagenidium giganteum Couch against mosquito larvae, M. anisopliae against cockroaches and flies, Aschersonia aleyrodis Webber against whiteflies, and B. bassiana against codling moth, Colorado potato beetle and other species from the order of Coleoptera and Lepidoptera can be applied (İnanlı et al. 2012).

Bauveria bassiana, which is abundant in agricultural lands worldwide, has a lot of hosts (Güven et al. 2014). To date, it was pointed out that B. bassiana has 707 different hosts, and these include 521 genera, 149 families and 15 orders (Zimmermann 2007). B. bassiana causes disease in species from the orders of Lepidoptera, Coleoptera, Hymenoptera, Diptera, Hemiptera, Orthoptera, Siphonaptera, Isoptera, Thysanoptera, Mantodea, Neuroptera, Dermaptera, Blattariae and Embioptera (Zimmermann 2007). It was reported that B. bassiana, developed specifically for China, is used in the struggle against European maize borer Ostrinia nubilalis Hbn. (Lepidoptera: Crambidae) and Pine lappets Dendrolimus spp. (Lepidoptera: Lasiocampidae). Entomopathogenic fungi B. bassiana was reported also in Turkey that can be used effectively in the controlling of Colorado potato beetle Leptinotarsa decemlineata Say. (Coleoptera: Chrysomelidae) (Azizoğlu et al. 2012). In the same study, it was reported that most of the entomopathogenic fungi were generally applied by the producers in the control of fruit flies and common cockchafers in ecological culture of perennial plants, and aphids and whiteflies in vegetable and greenhouse cultivation.

In this study, in order to determine the effects of $10^{6}, 10^{7}$ and $10^{8}$ conidia $\mathrm{mL}^{-1}$ doses of LD.2016 and M6-4 isolates of the entomopathogenic fungus $B$. bassiana on $M$. persicae, some life table parameters were calculated and the Weibull and Enkegaard mathematical models were applied to some of the obtained data. In addition, it was discussed whether it is possible to use these isolates as a biological control agent in the controlling of the pest within the scope of integrated pest management.

\section{Material and Methods}

\subsection{Production of pepper plants and Myzus persicae}

After filling half of $5 \mathrm{~L}$ plastic pots with a mixture of sterilized peat, soil and perlite in the ratio of 1:1:1, the process of transplanting was performed by planting pepper (Capsicum annuum L.) (Solanaceae) seedlings (Üç burun F1.) therein. Then, these pots which the pepper seedlings were planted in were kept in the clean climate cabinet, and maintenance and irrigation process were carried out when considered necessary. When the pepper plants reached approximately $10 \mathrm{~cm}$, they were brought to the insect rearing cabinet and infected with Myzus persicae Sulzer (Hemiptera: Aphididae). The conditions set to $25 \pm 1{ }^{\circ} \mathrm{C}$ temperature, $60 \pm 5 \% \mathrm{RH}$ and 16:8 $\mathrm{h}(\mathrm{L}: \mathrm{D})$ photoperiod in both the clean plant growing cabinet and the insect rearing cabinet. In order to ensure the continuity of insect culture, the collapsed plants were replaced with fresh those when necessary. Also diseased and damaged plants were removed from the climate cabinets. During the experiments, no pesticides and fertilizers were applied to the pepper plants.

\subsection{Preparation of entomopathogenic fungus suspension}

The isolates of Beauveria bassiana (Bals.) Vuill (BMAUM M6-4 and BMAUM LD.2016) used in this study were provided from the investigation of Baydar et al. (2016).

Entomopathogenic fungus isolates used in the experiment were cultured on Sabouraud Dextrose Agar (SDA) medium. SDA $\left(65 \mathrm{~g} / \mathrm{L}\right.$, Biolife $\left.^{\circledR}\right)$ medium was prepared with distilled water $\left(\mathrm{dH}_{2} \mathrm{O}\right)$ and filled in $500 \mathrm{~mL}$ glass erlenmayer flasks and sterilized in autoclave at $121{ }^{\circ} \mathrm{C}$ for 20 minutes. Cooled to room temperature, sterilized SDA medium was poured into petri dishes $(\varnothing 9 \mathrm{~cm})$ to form a new fungal culture.

Entomopathogenic fungus spores were taken from pure cultures and spread to petri dishes containing 12-15 mL of medium, and fresh culture was established under aseptic conditions. Petri dishes were incubated at $20-25{ }^{\circ} \mathrm{C}$ and $75 \%$ rh in the dark.

Spore suspensions were prepared by adding the spores collected by gently scraping from the 14-day old fungus cultures

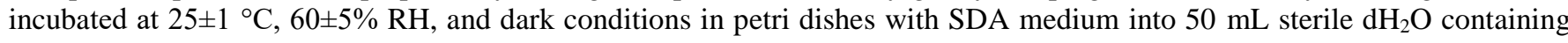
$0.05 \%$ Tween 80 .

The doses of the prepared spore suspensions were adjusted as $10^{6}, 10^{7}$ and $10^{8}$ conidia $\mathrm{mL}^{-1}$ to be applied on $M$. persicae by the help of a Thoma lam and a light microscope.

\subsection{Estabilisment of the experiments}

Ten $4^{\text {th }}$-instar nymphs, randomly selected from $M$. persicae individuals in the insect rearing cabinet, were transferred onto a pepper leaf in a petri dish with blotter paper on the base. These aphids, which reached adulthood, were checked every day and 
50 newborn aphids $\left(1^{\text {st }}\right.$-instar nymphs) were transferred separately to clean pepper leaves in petri dishes. Then, moults of the offsprings were checked daily and the waste skins (exuviae) were removed from the environment. Daily counts, in this way, were performed until all individuals died. When the offspring in each petri dish reached the $2^{\text {nd }}$ or $3^{\text {rd }}$ nymph stage, they were transferred separately to petri dishes containing pepper leaves that were immersed for five seconds in the prepared spore suspension of entomopathogenic fungus. This process was carried out separately for all three doses $\left(10^{6}, 10^{7}\right.$ and $10^{8}$ conidia $\mathrm{mL}^{-1}$ ) of B. bassiana's LD.2016 and M6-4 isolates.

As for the control application used in order to compare the effectiveness of the doses of both isolates, pepper leaves immersed in sterile $\mathrm{dH}_{2} \mathrm{O}$ containing $0.05 \%$ Tween 80 for five seconds were used. Thus, 50 repetitions were created for each application.

To monitor the growth of entomopathogenic fungi, the dead aphids were taken on lams in petri dishes containing moistened blotting paper and mycelial development was examined under a binocular stereo microscope (Figure 1). The experiments were stored in climatic cabinets at $25 \pm 1^{\circ} \mathrm{C}$ and $60 \pm 10 \% \mathrm{RH}$, and 16 hours light and 8 hours dark conditions.

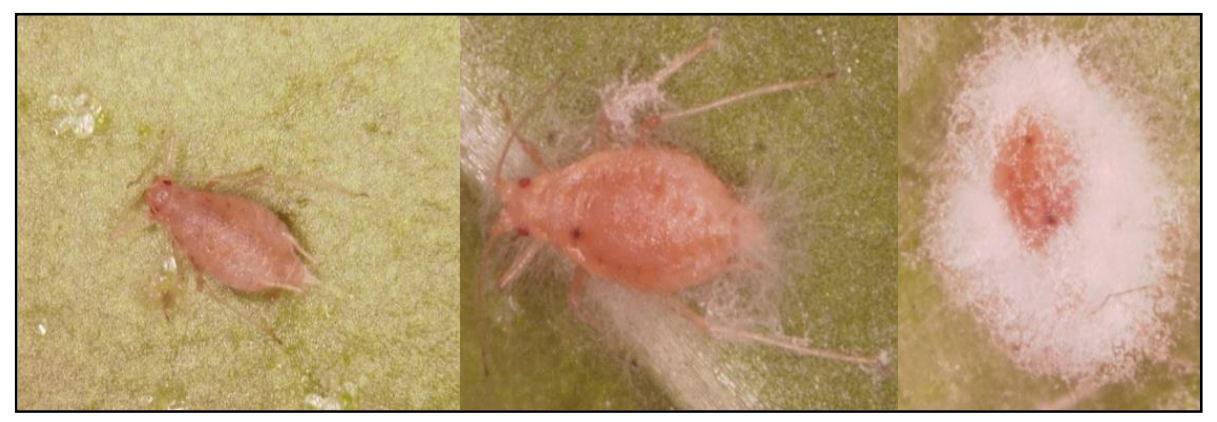

Figure 1- The stages of fungus development in Myzus persicae individuals exposed to LD.2016 and M6-4 isolates of Beauveria bassiana.

\subsection{Data analysis and assessments}

The age-related survival rate $\left(l_{x}\right.$, females/day) of all individuals and the age-related fertility rate ( $\mathrm{m}_{\mathrm{x}}$, females/female/day) obtained by multiplying the average number of offspring by the sex factor were computed based on recorded daily data until all individuals died (Birch 1948). Net reproductive rate $\left(\mathrm{R}_{0}\right.$, females/female), that is, the average number of offspring bred by a female individual as long as her lifetime was calculated according to the formula, $R_{0}=\sum l_{x}$. $m_{x}$ (Birch 1948). Next, by using the Euler-Lotka equation $\left(\sum e^{\left(-r_{m} x\right)} l_{x} m_{x}=1\right)$, Intrinsic rate of increase $\left(\mathrm{r}_{\mathrm{m}}\right.$, females/ female/day) was calculated. Then, mean generation time ( $\mathrm{T}_{0}$, day) was found according to the formula, $T_{0}=\frac{\ln R_{0}}{r_{m}}$, gross reproduction rate (GRR, females/female) according to the formula, $G R R=\sum m_{x}$ and finite rate of increase ( $\lambda$, females/female/day) according to the formula, $\lambda=e^{r_{m}}$ (Birch, 1948). Meanwhile, theoretical population-doubling time ( $\mathrm{T}_{2}$, day) was also computed according to the formula, $T_{2}=$ $\frac{\ln 2}{r_{m}}$ (Kairo \& Murphy 1995). The variable " $\mathrm{x}$ " in the formulas indicates the age in days of the female individuals, the coefficient "e" denotes Euler's number which is a mathematical constant (approximately equal to 2.71828) and the symbol "ln" represents the natural logarithm (logarithm based on the coefficient "e"). To use the intrinsic rate of increase ( $\mathrm{r}_{\mathrm{m}}$ ) values computed on the data obtained from these populations in comparison test, the pseudo- $\mathrm{r}_{\mathrm{m}}$ values and the standard errors thereof were calculated by the Bootstrap resampling method with the estimates 2000 times (Meyer et al. 1986; Lawo \& Lawo 2011; Huang \& Chi 2012; Yu et al. 2013a, b). Later, one-way analysis of variance (One-Way ANOVA) followed by Tukey multiple comparison test (Tukey 1949) was performed. Statistical analyses were done by IBM ${ }^{\circledR}$ SPSS $^{\circledR}$ Statistics (Version 20.0, August 2011, SPSS Inc., Chicago, IL, USA) and MS Excel 2010 (Version 14.0) programs.

The two-parameter Weibull frequency distribution was used to define the age-related survival rate $\left(l_{\mathrm{x}}\right)$ of the populations. The parameters of this mathematical distribution model were estimated according to the formula, $S_{p}(x)=e^{\left[-\left(\frac{x}{b}\right)^{c}\right]}, x, b, c>$ 0 and in the formula, the " $S_{p}(x)$ " value indicates the probability of the survival rate at a certain age in days; the "b" and "c" values denote scale and shape parameters of the curve, respectively (Deevey 1947; Pinder et al. 1978; Tingle \& Copland 1989; Wang et al. 2000). Meanwhile, the Enkegaard regression model $\left(F_{(x)}=a \cdot x \cdot e^{(-b x)}\right)$ was used to define the age-related fertility rate $\left(\mathrm{m}_{\mathrm{x}}\right)$ of adult females. Where " $F_{(x)}$ " is the probability of fecundity at a certain age in days, the " $\mathrm{x}$ " value is the female's age in days, the "a" and "b" values denote constant parameters (Enkegaard 1993; Hansen et al. 1999). The parameters of both mathematical models, the two-parameter Weibull distribution and the Enkegaard regression, were estimated by using SigmaPlot $^{\circledR}$ (Version 11.0, Systat Software, Inc., San Jose California, USA) package program. The values coefficient of determination $\left(\mathrm{R}^{2}\right)$, and residual sum of squares (RSS) were used as criteria for the degree of conformity of the Weibull and Enkegaard models to the data obtained (Kontodimas et al. 2004). 


\section{Results and Discussion}

The age-related survival rate $\left(1_{\mathrm{x}}\right)$ of $M$. persicae individuals exposed to $10^{6}$ and $10^{8}$ conidia $\mathrm{mL}^{-1}$ doses of $B$. bassiana's LD.2016 isolate started to decrease after the $6^{\text {th }}$ day and the individuals exposed to $10^{7}$ conidia $\mathrm{mL}^{-1}$ dose after the $4^{\text {th }}$ day. It was observed that all $M$. persicae individuals exposed to $10^{6}, 10^{7}$ and $10^{8}$ conidia $\mathrm{mL}^{-1}$ doses of LD.2016 isolate were died on the $32^{\text {nd }}, 18^{\text {th }}$ and $13^{\text {th }}$ days, respectively. As for M6-4 isolate, the age-related survival rate $\left(1_{\mathrm{x}}\right)$ of $M$. persicae individuals exposed to $10^{6}, 10^{7}$ and $10^{8}$ conidia $\mathrm{mL}^{-1}$ doses began to decrease after the $8^{\text {th }}, 7^{\text {th }}$ and $1^{\text {st }}$ days, respectively. It was determined that all M. persicae individuals exposed to $10^{6}$ conidia $\mathrm{mL}^{-1}$ dose of M6-4 isolate were died on the $33^{\text {rd }}$ day, and all individuals in the both groups, exposed to $10^{7}$ and $10^{8}$ conidia $\mathrm{mL}^{-1}$ doses, were died on the $19^{\text {th }}$ day (Figure 2 ). The onset of the decrease in the age-related survival rate $\left(1_{\mathrm{x}}\right)$ of the control group was determined as the $7^{\text {th }}$ day and all individuals were died on the $41^{\text {st }}$ day (Figure 3).
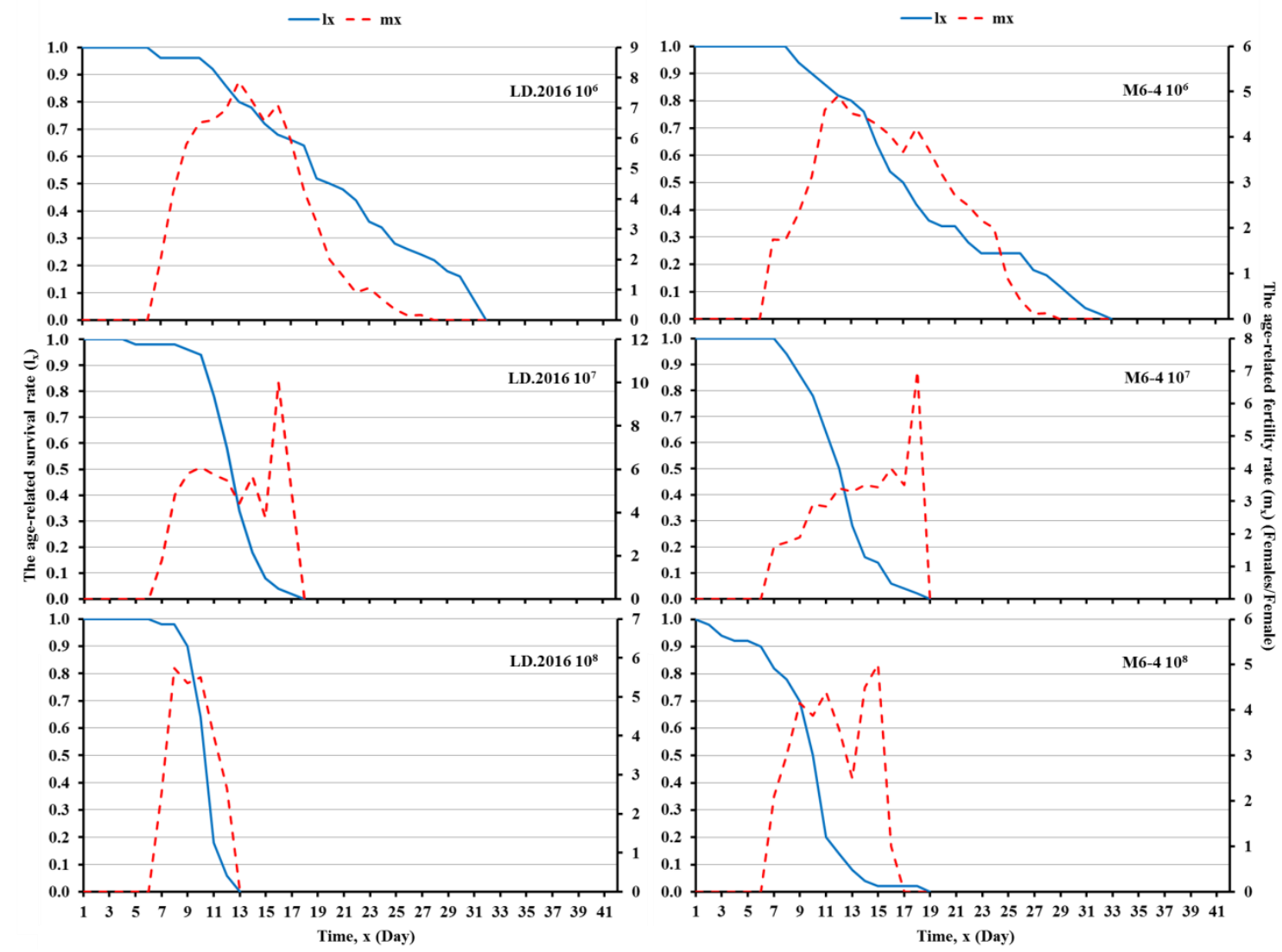

Figure 2- The age-related survival rate $\left(l_{x}\right)$ and the age-related fertility rate $\left(m_{x}\right)$ of Myzus persicae individuals exposed to different doses of Beauveria bassiana's LD.2016 and M6-4 isolates

The individuals exposed to three different doses of B. bassiana's LD.2016 and M6-4 isolates, and adults in the control group began to give offspring from the $7^{\text {th }}$ day. M. persicae adults exposed to $10^{6}$ conidia $\mathrm{mL}^{-1}$ dose of $B$. bassiana's LD.2016 isolate gave the maximum offspring as 7.88 offsprings on the $13^{\text {th }}$ day, the individuals exposed to $10^{7}$ conidia $\mathrm{mL}^{-1} \mathrm{dose}$ as 10 offsprings on the $16^{\text {th }}$ day, and the individuals exposed to $10^{8}$ conidia $\mathrm{mL}^{-1}$ dose as 5.74 offsprings on the $8^{\text {th }}$ day. As for M6-4 isolate, $M$. persicae adults exposed to $10^{6}$ conidia $\mathrm{mL}^{-1}$ dose gave the maximum offspring as 4.90 offsprings on the $12^{\text {th }}$ day, the individuals exposed to $10^{7}$ conidia $\mathrm{mL}^{-1}$ dose as 7 offsprings on the $18^{\text {th }}$ day, and the individuals exposed to $10^{8} \mathrm{conidia}^{\mathrm{mL}}$ ${ }^{1}$ dose as 5 offsprings on the $15^{\text {th }}$ day (Figure 2). M. persicae adults in the control group had the most newborn as 4.69 offsprings on the $17^{\text {th }}$ day (Figure 3). The curves drawn over $1_{x}$ and $m_{x}$ values obtained from the individuals exposed to $10^{7}$ and $10^{8}$ conidia $\mathrm{mL}^{-1}$ doses of LD.2016 and M6-4 isolates showed similar fluctuations. Again, the curves drawn over $1_{\mathrm{x}}$ and $\mathrm{m}_{\mathrm{x}}$ values obtained from both of the individuals exposed to $10^{6}$ conidia $\mathrm{mL}^{-1}$ dose of two isolates and the individuals in the control group were found to be almost similar. As the dose increased, the curves of the $1_{\mathrm{x}}$ and $\mathrm{m}_{\mathrm{x}}$ values tended to decrease in a shorter time than those of the control group (Figures 2 and 3). 


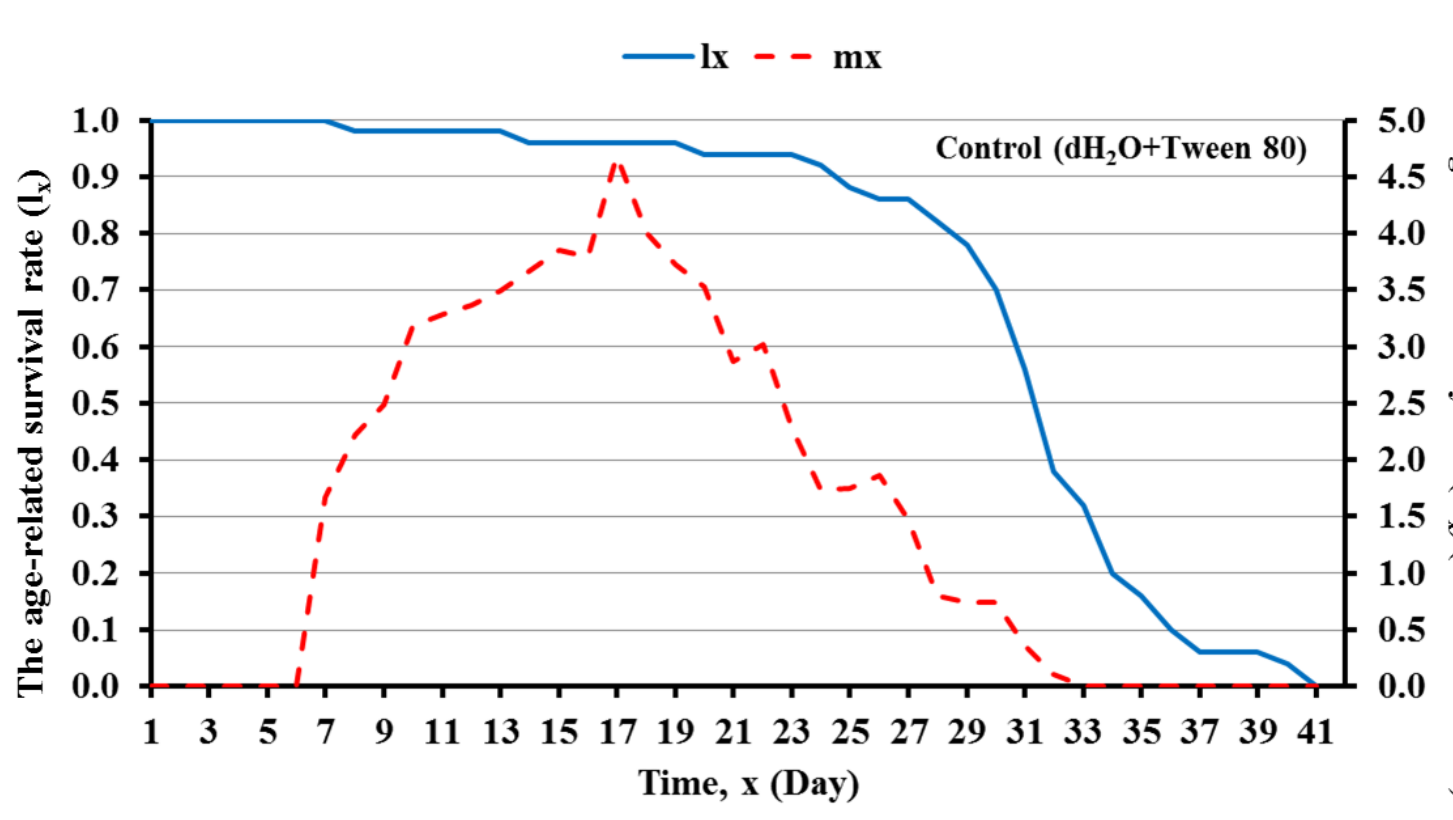

Figure 3- The age-related survival rate $\left(l_{x}\right)$ and the age-related fertility rate $\left(m_{x}\right)$ of Myzus persicae individuals used as the control group

Rashki and Shirvani (2013) found that fluctuations in the curves of $1_{\mathrm{x}}$ and $\mathrm{m}_{\mathrm{x}}$ values obtained from A. gossypii individuals exposed to low concentrations $\left(5.6 \times 10^{2}, 10^{4}\right.$ and $10^{5}$ conidia $\left.\mathrm{mL}^{-1}\right)$ of $B$. bassiana and the individuals in the control group

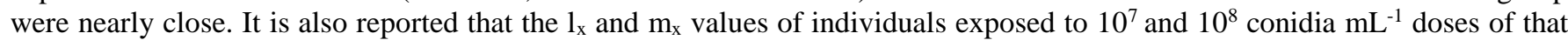
entomopathogenic fungus were close to each other. As a result, it is stated that as the conidial concentration increases, the values of $l_{\mathrm{x}}$ and $\mathrm{m}_{\mathrm{x}}$ decrease. It was observed that the results obtained from this study are in line with the results of the present study. Table 1 shows the development and lifetimes in different biological stages of $M$. persicae individuals exposed to different doses of B. bassiana's LD.2016 and M6-4 isolates.

The durations of the first nymphal stages of $M$. persicae individuals exposed to different doses of two isolates, and individuals in the control group showed variety between 1.56 and 1.82 days, and statistically all were included in the same group. Development times of the LD.2016 isolate- and M6-4 isolate-exposed M. persicae individuals were in the same statistical group as the control group, except those exposed to $10^{8}$ conidia $\mathrm{mL}^{-1}$ dose of M6-4 isolate. The highest lifespan was in the control group with 30.16 days, and the lifespans of the LD.2016 isolate- and M6-4 isolate-exposed individuals (under the same dose conditions, $10^{6}$ and $10^{7}$ conidia $\mathrm{mL}^{-1}$ ) were found as similar. The shortest lifespans were calculated as 9.74 and 9.00 days from individuals exposed to $10^{8}$ conidia $\mathrm{mL}^{-1}$ doses of LD.2016 and M6-4 isolates, respectively (Table 1). 
Table 1- The development times and lifespans (day) of Myzus persicae individuals exposed to different doses of Beauveria bassiana's LD.2016 and M6-4 isolates*

\begin{tabular}{|c|c|c|c|c|c|}
\hline Biological Stages & Isolate & Dose & $n$ & Duratio & \\
\hline \multirow{7}{*}{ The $1^{\text {st }}$ Nymphal Stage } & Control & & 50 & $1.68 \pm 0.07$ & $\mathrm{a}$ \\
\hline & & $10^{6}$ & 50 & $1.82 \pm 0.10$ & a \\
\hline & LD.2016 & $10^{7}$ & 50 & $1.70 \pm 0.11$ & $a$ \\
\hline & & $10^{8}$ & 50 & $1.74 \pm 0.12$ & $a$ \\
\hline & & $10^{6}$ & 50 & $1.74 \pm 0.08$ & a \\
\hline & M6-4 & $10^{7}$ & 50 & $1.56 \pm 0.07$ & a \\
\hline & & $10^{8}$ & 50 & $1.80 \pm 0.10$ & $\mathrm{a}$ \\
\hline \multirow{7}{*}{ The $2^{\text {nd }}$ Nymphal Stage } & Control & & 50 & $1.64 \pm 0.08$ & $\mathrm{ab}$ \\
\hline & & $10^{6}$ & 50 & $1.36 \pm 0.08$ & $\mathrm{bc}$ \\
\hline & LD.2016 & $10^{7}$ & 49 & $1.40 \pm 0.09$ & $\mathrm{bc}$ \\
\hline & & $10^{8}$ & 49 & $1.32 \pm 0.09$ & $\mathrm{bc}$ \\
\hline & & $10^{6}$ & 50 & $1.80 \pm 0.06$ & $\mathrm{a}$ \\
\hline & M6-4 & $10^{7}$ & 50 & $1.78 \pm 0.07$ & a \\
\hline & & $10^{8}$ & 47 & $1.22 \pm 0.10$ & c \\
\hline \multirow{7}{*}{ The $3^{\text {rd }}$ Nymphal Stage } & Control & & 50 & $1.60 \pm 0.08$ & bc \\
\hline & & $10^{6}$ & 49 & $1.24 \pm 0.08$ & $\mathrm{~cd}$ \\
\hline & LD.2016 & $10^{7}$ & 49 & $1.22 \pm 0.07$ & d \\
\hline & & $10^{8}$ & 49 & $1.40 \pm 0.08$ & $\mathrm{~cd}$ \\
\hline & & $10^{6}$ & 50 & $2.00 \pm 0.08$ & a \\
\hline & M6-4 & $10^{7}$ & 50 & $1.92 \pm 0.08$ & $\mathrm{ab}$ \\
\hline & & $10^{8}$ & 44 & $1.50 \pm 0.13$ & $\mathrm{~cd}$ \\
\hline \multirow{7}{*}{ The $4^{\text {th }}$ Nymphal Stage } & Control & & 49 & $1.90 \pm 0.10$ & $a b c$ \\
\hline & & $10^{6}$ & 48 & $2.30 \pm 0.12$ & $\bar{a}$ \\
\hline & LD.2016 & $10^{7}$ & 49 & $2.14 \pm 0.11$ & $\mathrm{ab}$ \\
\hline & & $10^{8}$ & 49 & $2.02 \pm 0.12$ & $\mathrm{ab}$ \\
\hline & & $10^{6}$ & 46 & $1.72 \pm 0.11$ & $\mathrm{bc}$ \\
\hline & M6-4 & $10^{7}$ & 48 & $1.66 \pm 0.11$ & $\mathrm{bc}$ \\
\hline & & $10^{8}$ & 38 & $1.44 \pm 0.16$ & c \\
\hline \multirow{7}{*}{ Development Time } & Control & & 49 & $6.72 \pm 0.17$ & $\mathrm{a}$ \\
\hline & & $10^{6}$ & 48 & $6.73 \pm 0.16$ & $\mathrm{a}$ \\
\hline & LD.2016 & $10^{7}$ & 49 & $6.42 \pm 0.16$ & a \\
\hline & & $10^{8}$ & 49 & $6.46 \pm 0.16$ & $\mathrm{a}$ \\
\hline & & $10^{6}$ & 46 & $6.76 \pm 0.31$ & $\mathrm{a}$ \\
\hline & M6-4 & $10^{7}$ & 48 & $6.70 \pm 0.22$ & $\mathrm{a}$ \\
\hline & & $10^{8}$ & 38 & $5.26 \pm 0.43$ & $\mathrm{~b}$ \\
\hline \multirow{7}{*}{ Lifespan } & Control & & 50 & $30.16 \pm 0.82$ & $\mathrm{a}$ \\
\hline & & $10^{6}$ & 50 & $19.96 \pm 1.02$ & $\mathrm{~b}$ \\
\hline & LD.2016 & $10^{7}$ & 50 & $11.84 \pm 0.30$ & c \\
\hline & & $10^{8}$ & 50 & $9.74 \pm 0.16$ & $\mathrm{~cd}$ \\
\hline & & $10^{6}$ & 50 & $18.06 \pm 0.98$ & $\mathrm{~b}$ \\
\hline & M6-4 & $10^{7}$ & 50 & $11.42 \pm 0.36$ & $\mathrm{~cd}$ \\
\hline & & $10^{8}$ & 50 & $9.00 \pm 0.43$ & $\mathrm{~d}$ \\
\hline
\end{tabular}

*The means ( \pm standard errors) with different letters within the same column, separately for each biological stage, differ significantly at the 0.05 level according to Tukey's HSD test.

Preoviposition durations of both the individuals exposed to different doses of $B$. bassiana isolates and the individuals in the control group varied between 0.00 and 0.36 days, and all of them were statistically in the same group, except those exposed to $10^{6}$ conidia $\mathrm{mL}^{-1}$ dose of M6-4 isolate. Oviposition and postoviposition durations of the LD.2016 isolate- and M6-4 isolateexposed (at the different doses) individuals were, so that within itself, statistically included in the same group. In addition, it was observed that as the dose increased, the periods of oviposition and postoviposition shorten. The longest oviposition and postoviposition durations were seen in the control group and were calculated as 18.41 and 5.37 days, respectively (Table 2). 
Table 2- Daily (females/female/day) and total (females/female) numbers of offspring of Myzus persicae individuals exposed to different doses of Beauveria bassiana's LD.2016 and M6-4 isolates*

\begin{tabular}{|c|c|c|c|c|c|c|c|}
\hline & Dose & $n$ & $\begin{array}{c}\text { Preoviposition } \\
\text { Duration }\end{array}$ & $\begin{array}{c}\text { Oviposition } \\
\text { Duration }\end{array}$ & $\begin{array}{c}\text { Postoviposition } \\
\text { Duration }\end{array}$ & $\begin{array}{c}\text { Daily number of } \\
\text { offspring }\end{array}$ & $\begin{array}{c}\text { Total number of } \\
\text { offspring }\end{array}$ \\
\hline & Control & 49 & $0.00 \pm 0.00 \mathrm{~b}$ & $18.41 \pm 0.59 \mathrm{a}$ & $5.37 \pm 0.48 \mathrm{a}$ & $2.51 \pm 0.11 \mathrm{~b}$ & $59.60 \pm 2.92 \mathrm{a}$ \\
\hline \multirow{3}{*}{ 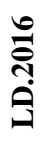 } & $10^{6}$ & 48 & $0.00 \pm 0.00 \mathrm{~b}$ & $11.50 \pm 0.66 b$ & $2.17 \pm 0.54 b$ & $4.85 \pm 0.22 \mathrm{a}$ & $60.84 \pm 3.53 \mathrm{a}$ \\
\hline & $10^{7}$ & 49 & $0.10 \pm 0.04 \mathrm{~b}$ & $5.35 \pm 0.26 \mathrm{c}$ & $0.00 \pm 0.00 \mathrm{c}$ & $4.94 \pm 0.21 \mathrm{a}$ & $27.68 \pm 1.88 b$ \\
\hline & $10^{8}$ & 49 & $0.00 \pm 0.00 \mathrm{~b}$ & $3.18 \pm 0.15 \mathrm{~cd}$ & $0.04 \pm 0.04 \mathrm{c}$ & $4.85 \pm 0.20 \mathrm{a}$ & $15.68 \pm 0.88 c$ \\
\hline \multirow{3}{*}{ 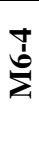 } & $10^{6}$ & 44 & $0.36 \pm 0.10 \mathrm{a}$ & $10.21 \pm 0.71 b$ & $1.43 \pm 0.44 b c$ & $2.75 \pm 0.21 b$ & $34.86 \pm 3.87 \mathrm{~b}$ \\
\hline & $10^{7}$ & 48 & $0.02 \pm 0.02 b$ & $4.52 \pm 0.34 \mathrm{~cd}$ & $0.08 \pm 0.05 \mathrm{c}$ & $2.27 \pm 0.18 b$ & $11.52 \pm 1.37 \mathrm{c}$ \\
\hline & $10^{8}$ & 38 & $0.13 \pm 0.06 b$ & $3.16 \pm 0.25 \mathrm{~d}$ & $0.05 \pm 0.05 \mathrm{c}$ & $2.62 \pm 0.25 b$ & $8.90 \pm 1.07 \mathrm{c}$ \\
\hline
\end{tabular}

*The means ( \pm standard errors) with different letters within the same column differ significantly at the 0.05 level according to Tukey’s HSD test.

Daily numbers of offspring of the individuals exposed to different doses of B. bassiana's LD.2016 and M6-4 isolates and the individuals in the control group varied between 2.27 and 4.94 females/female/day, and the highest daily number of offspring was seen in the individuals exposed to $10^{7}$ conidia $\mathrm{mL}^{-1}$ dose of LD.2016. The least total numbers of offspring was seen in the individuals exposed to $10^{8}$ conidia $\mathrm{mL}^{-1}$ dose of M6-4 isolate with 8.90 females/female, and the highest in the individuals exposed to $10^{6}$ conidia $\mathrm{mL}^{-1}$ dose of LD.2016 isolate with 60.84 females/female. This was followed by M. persicae individuals in the control group with 59.60 females/female. The difference between the minimum and maximum total numbers of offspring was found to be statistically significant (Table 2). In the study on sub-lethal effect of M. anisopliae of Rashki et al. (2015), it was stated that the sub-lethal concentration of the entomopathogenic fungus has no effect on fertility of $M$. persicae.

Life table parameters of M. persicae individuals exposed to different doses of B. bassiana's LD.2016 and M6-4 isolates are seen in Table 3. The difference between the intrinsic rate of increase $\left(\mathrm{r}_{\mathrm{m}}\right)$ and net reproductive rate $\left(\mathrm{R}_{0}\right)$ values of $M$. persicae individuals exposed to different doses of both isolates were found statistically significant.

The longest mean generation time $\left(\mathrm{T}_{0}\right)$ was determined in $M$. persicae individuals in the control group with 12.950 days, and the shortest in individuals exposed to $10^{8}$ conidia $\mathrm{mL}^{-1}$ dose of LD.2016 with 8.497 days (Table 3).

The gross reproduction rate (GRR) of $M$. persicae individuals in the control group was calculated as 64.702 females/female, and this value was computed as 81.105, 58.596 and 25.827 females/female, respectively, in the individuals exposed to $10^{6}, 10^{7}$ and $10^{8}$ conidia $\mathrm{mLl}^{-1}$ doses of $B$. bassiana's LD.2016 isolate. The value was also determined for the individuals exposed to $10^{6}, 10^{7}$ and $10^{8}$ conidia $\mathrm{mL}^{-1}$ doses of B. bassiana's M6-4 isolate as $61.456,39.097$ and 34.103 females/female, respectively. The theoretical population-doubling time $\left(\mathrm{T}_{2}\right)$ was seen as the longest in the individuals exposed to $10^{7}$ conidia $\mathrm{mL}^{-1}$ dose of M6-4 isolate with 2.631 days, and as the shortest in the individuals exposed to $10^{6}$ conidia $\mathrm{mL}^{-1}$ dose of LD.2016 isolate with 1.869 days. The highest finite rate of increase $(\lambda)$ was observed in the individuals exposed to $10^{6}$ conidia $\mathrm{mL}^{-1}$ dose of LD.2016 isolate with 1.449 females/female/day, while the lowest was in the individuals exposed to $10^{7}$ conidia $\mathrm{mL}^{-1}$ dose of M6-4 isolate with 1.301 females/female/day (Table 3).

Table 3- Life table parameters of Myzus persicae individuals exposed to different doses of Beauveria bassiana's LD.2016 and M6-4 isolates

\begin{tabular}{|c|c|c|c|c|c|c|c|}
\hline \multirow{2}{*}{ Parameters } & \multirow{2}{*}{ Control } & \multicolumn{3}{|c|}{ LD.2016 } & \multicolumn{3}{|c|}{ M6-4 } \\
\hline & & $10^{6}$ & $10^{7}$ & $10^{8}$ & $10^{6}$ & $10^{7}$ & $10^{8}$ \\
\hline Intrinsic rate of increase, $r_{m}$ & $0.280 \mathbf{e}$ & $0.340 \mathbf{b}$ & $0.352 \mathbf{a}$ & $0.337 \mathbf{c}$ & $0.292 \mathrm{~d}$ & $0.263 \mathbf{g}$ & $0.268 \mathbf{f}$ \\
\hline Net reproductive rate, $R_{0}$ & $59.71 \mathbf{b}$ & $61.19 \mathbf{a}$ & $27.82 \mathrm{~d}$ & $15.72 \mathrm{e}$ & $34.90 \mathrm{c}$ & $11.60 \mathrm{f}$ & $8.93 \mathbf{g}$ \\
\hline Mean generation time, $\mathbf{T}_{0}$ & 12.950 & 11.152 & 9.534 & 8.497 & 11.647 & 9.775 & 8.836 \\
\hline Gross reproduction rate, GRR & 64.702 & 81.105 & 58.596 & 25.827 & 61.456 & 39.097 & 34.103 \\
\hline Theoretical population-doubling time, $\mathbf{T}_{2}$ & 2.182 & 1.869 & 1.967 & 2.064 & 2.229 & 2.631 & 2.575 \\
\hline Finite rate of increase, $\lambda$ & 1.374 & 1.449 & 1.422 & 1.399 & 1.365 & 1.301 & 1.309 \\
\hline n & 40 & 31 & 17 & 12 & 32 & 18 & 18 \\
\hline
\end{tabular}

*: The values of intrinsic rate of increase $\left(r_{m}\right)$ and net reproductive rate $\left(R_{0}\right)$ with different letters within the same line differ significantly at the 0.05 level according to Tukey's HSD test.

Net reproductive rate $\left(\mathrm{R}_{0}\right)$ values of both the individuals exposed to LD.2016 isolate and the individuals exposed to M6-4 isolate differed by dose. It was observed that there is an inverse proportion between dose and $\mathrm{R}_{0}$ values. Rashki and Shirvani (2013) observed the effect of B. bassiana on the life table parameters of A. gossypii in their study, and determined that net reproductive rate $\left(\mathrm{R}_{0}\right)$ values decreased as concentration increased, as in the present study. 
The present study indicated that the mean generation time $\left(\mathrm{T}_{0}\right)$, finite rate of increase $(\lambda)$ and gross reproduction rate (GRR) values of both the individuals exposed to LD.2016 isolate and the individuals exposed to M6-4 isolate decreased as concentration increased, too. As for the theoretical population-doubling time $\left(\mathrm{T}_{2}\right)$, another life table parameter, increased in parallel with the concentration (Table 3). Rashki and Shirvani (2013) observed in their study that the mean generation time $\left(\mathrm{T}_{0}\right)$ and theoretical population-doubling time $\left(\mathrm{T}_{2}\right)$ values increased with concentration. However, they also stated that there was no significant difference between the individuals exposed to low concentrations $\left(5.6 \times 10^{2}, 1 \times 10^{4}\right.$ and $\left.1 \times 10^{5} \mathrm{conidia}^{-1}\right)$ and the individuals in control group in terms of $T_{0}$ and $T_{2}$ values. They also reported that the finite rate of increase $(\lambda)$ value was inversely proportional to the conidial concentration. The mean generation time $\left(\mathrm{T}_{0}\right)$, finite rate of increase $(\lambda)$ and theoretical population-doubling time $\left(\mathrm{T}_{2}\right)$ values were similar in both studies. Bayındır et al. (2016) examined the effect of some plant extracts on the biology of $M$. persicae, found the intrinsic rate of increase $\left(\mathrm{r}_{\mathrm{m}}\right)$, net reproductive rate $\left(\mathrm{R}_{0}\right)$, mean generation time $\left(\mathrm{T}_{0}\right)$, gross reproduction rate (GRR), theoretical population-doubling time $\left(\mathrm{T}_{2}\right)$, and finite rate of increase $(\lambda)$ values as $0.37,44.45,10.39,58.47,1.89$, and 1.44 females/female/day, respectively. As for the present study examining the effect of $B$. bassiana on the biology of $M$. persicae, calculated the intrinsic rate of increase $\left(\mathrm{r}_{\mathrm{m}}\right)$, net reproductive rate $\left(\mathrm{R}_{0}\right)$, mean generation time $\left(\mathrm{T}_{0}\right)$, gross reproduction rate (GRR), theoretical population-doubling time $\left(\mathrm{T}_{2}\right)$, and finite rate of increase $(\lambda)$ values as $0.280,59.71,12.950,64.702,2.182$ and 1.374 females/female/day, respectively (Table 3 ). The intrinsic rate of increase $\left(\mathrm{r}_{\mathrm{m}}\right)$ of $M$. persicae on pepper determined as 0.250 females/female/day in a study on demographic characteristics of the aphid carried out by Ricci et al. (2000). Another study done by La Rossa et al. (2013) calculated the intrinsic rate of increase $\left(\mathrm{r}_{\mathrm{m}}\right)$ of $M$. persicae ranged from 0.174 to 0.281 females/female/day on nine different pepper cultivars. Also, the intrinsic rate of increase $\left(r_{m}\right)$ was found as $0.319,0.356$ and 0.305 females/female/day for the offsprings of younger, middle and older aged mothers, respectively in the study of Birgücü and Bayındır-Erol (2018) about maternal age effect on biology of $M$. persicae. Again, the same study declared that the net reproductive rates $\left(\mathrm{R}_{0}\right)$ were $26.483,38.095$ and 21.474 females/female for the offsprings of younger, middle and older aged mothers, respectively.

The most fitted life curves based on the age-related survival rate $\left(1_{\mathrm{x}}\right)$ of $M$. persicae individuals exposed to different doses of B. bassiana's LD.2016 and M6-4 isolates were determined by the Weibull distribution model. As the criteria for the conformity degree of the Weibull distribution models to the obtained data, determination coefficient $\left(\mathrm{R}^{2}\right)$ and residual sum of squares (RSS) values were used (Kontodimas et al. 2004). The "b (scale)" and "c (shape)" parameters in the Weibull distribution models applied on the age-related survival rate $\left(l_{\mathrm{x}}\right)$ were calculated as 22.169 and 2.676 for the individuals exposed to $10^{6}$ conidia $\mathrm{mL}^{-1}$ dose of LD.2016 isolate, and as 19.539 and 2.534 for the individuals exposed to $10^{6}$ conidia $\mathrm{mL}^{-1}$ dose of M6-4 isolate. Based on these results, it was seen that the $M$. persicae populations exposed to $10^{6} \mathrm{conidia}^{-1}$ doses of both isolates had an increasing population type (Figure 4 and Table 4).

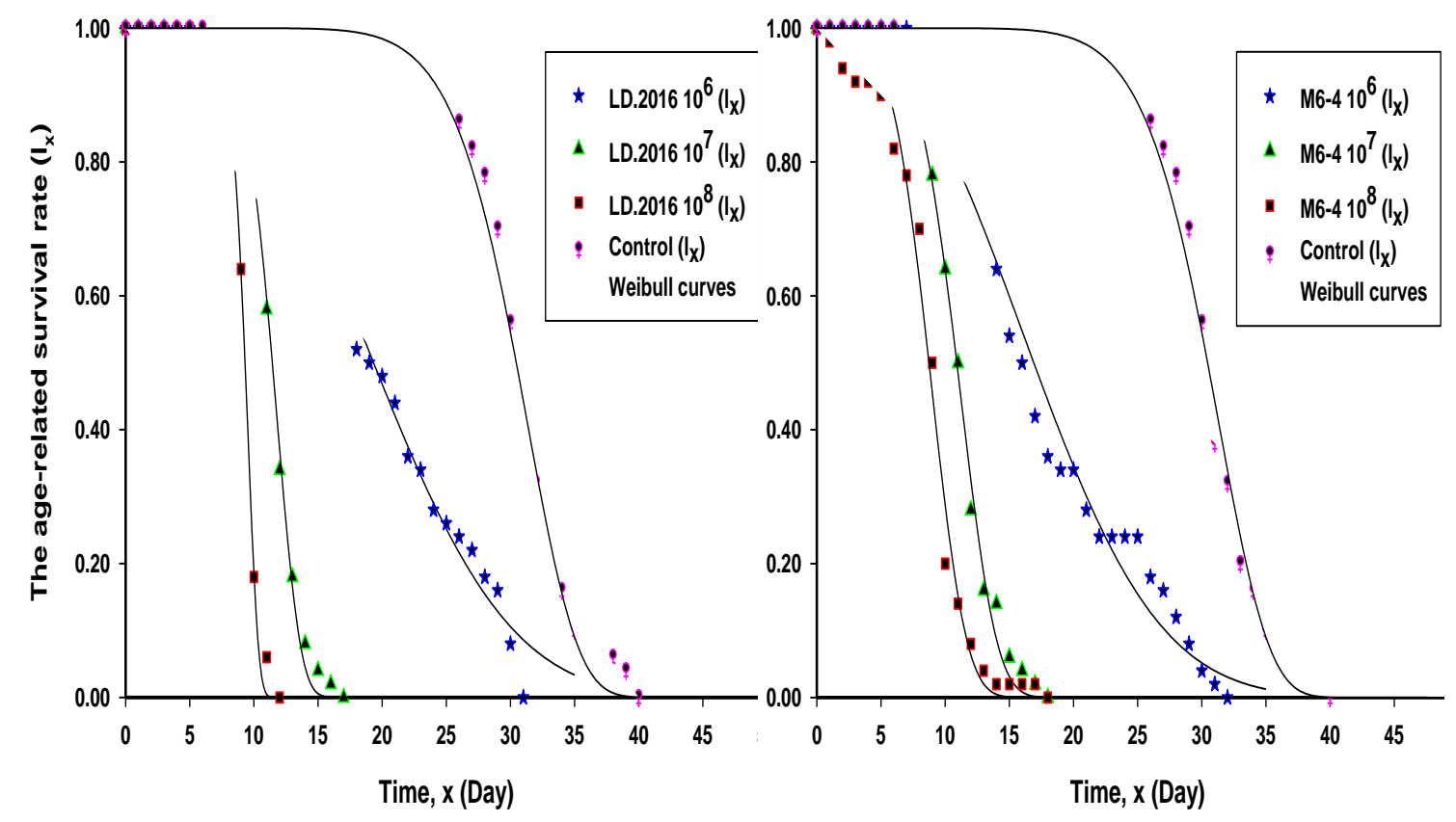

Figure 4- The Weibull distribution models fitted on the age-related survival rate (lx) of Myzus persicae individuals exposed to different doses of Beauveria bassiana's LD.2016 and M6-4 isolates 
Table 4- The parameters of the Weibull distribution models fitted on the age-related survival rate ( $\left.\mathrm{l}_{\mathrm{x}}\right)$ of Myzus persicae individuals exposed to different doses of Beauveria bassiana's LD.2016 and M6-4 isolates*

\begin{tabular}{|c|c|c|c|c|c|}
\hline & Dose & $b$ (scale) & $c$ (shape) & $R^{2}$ & $R S S$ \\
\hline \multicolumn{2}{|c|}{ Control } & $31.724 \pm 0.128$ & $8.945 \pm 0.403$ & 0.992 & 0.041 \\
\hline \multirow{3}{*}{ } & $10^{6}$ & $22.169 \pm 0.167$ & $2.676 \pm 0.079$ & 0.994 & 0.022 \\
\hline & $10^{7}$ & $12.017 \pm 0.059$ & $7.428 \pm 0.340$ & 0.997 & 0.008 \\
\hline & $10^{8}$ & $9.594 \pm 0.032$ & $12.359 \pm 0.622$ & 0.998 & 0.003 \\
\hline \multirow{3}{*}{$\sum_{i}^{\nabla}$} & $10^{6}$ & $19.539 \pm 0.256$ & $2.534 \pm 0.119$ & 0.986 & 0.061 \\
\hline & $10^{7}$ & $11.729 \pm 0.075$ & $5.049 \pm 0.212$ & 0.997 & 0.010 \\
\hline & $10^{8}$ & $9.510 \pm 0.139$ & $4.351 \pm 0.364$ & 0.989 & 0.035 \\
\hline
\end{tabular}

*The model parameters, $\mathrm{b}$, and c, are given with their standard errors $(\mathrm{P}<0.0001)$

For the individuals exposed to $10^{7}$ conidia $\mathrm{mL}^{-1}$ dose of LD.2016 isolate, the "b" and "c" parameters in the Weibull distribution models were calculated as 12.017 and 7.428, and these parameters were found as 19.539 and 2.534 for the

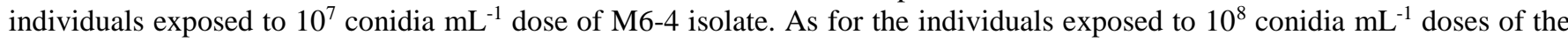
isolates, the parameters "b" and "c" were calculated as 9.594 and 12.359 for LD.2016 isolate-exposed individuals and as 9.510 and 4.351 for M6-4 isolate-exposed individuals (Table 4).
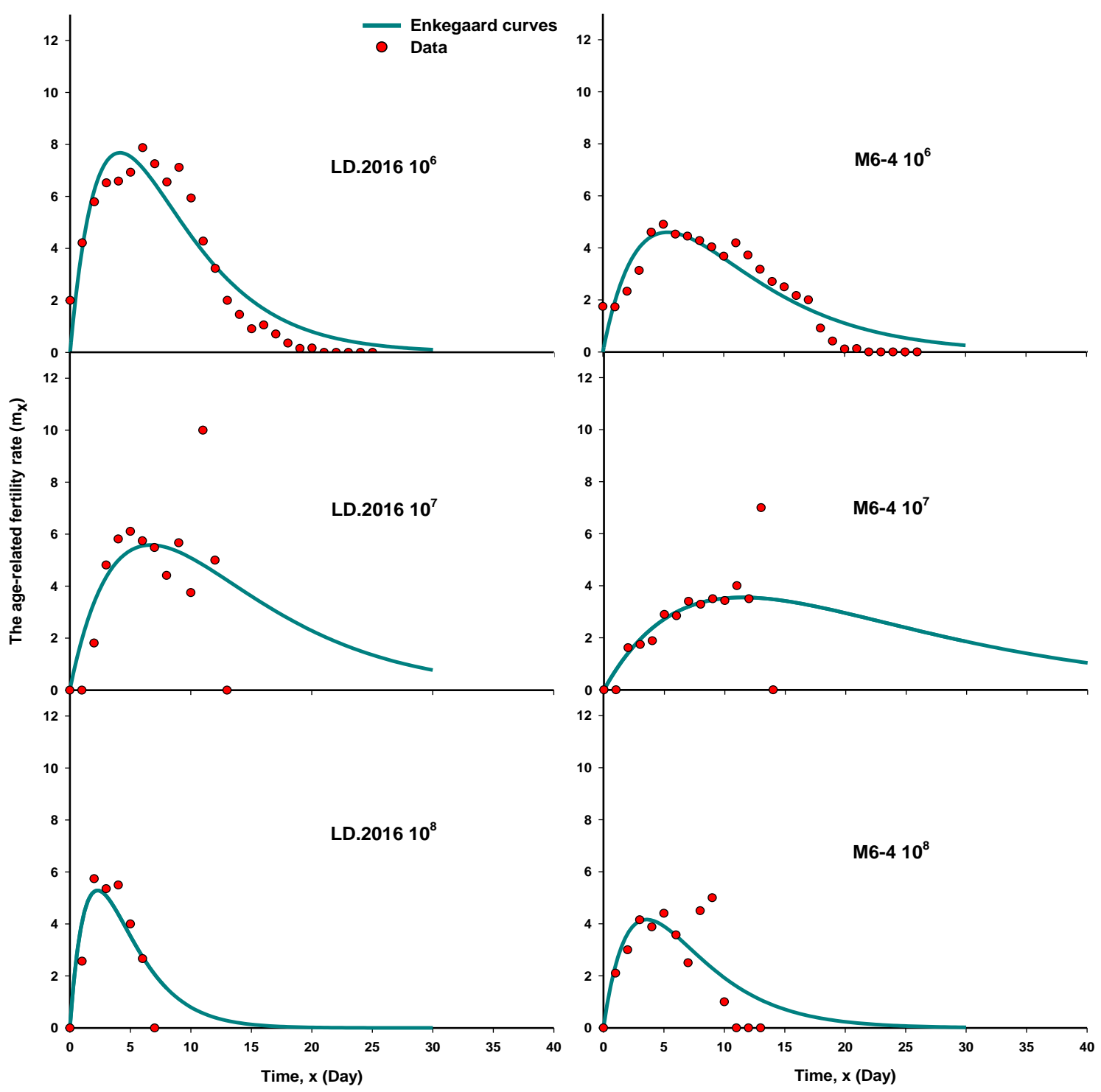

Figure 5- The Enkegaard regression models fitted on the age-related fertility rate $\left(\mathrm{m}_{\mathrm{x}}\right)$ of Myzus persicae individuals exposed to different doses of Beauveria bassiana's LD.2016 and M6-4 isolates 
According to these results, the curves of the Weibull distribution model fitted on the age-related survival rate $\left(1_{x}\right)$ of individuals exposed to $10^{7}$ and $10^{8}$ conidia $\mathrm{mL}^{-1}$ doses of both isolates tended to decrease earlier and suddenly with the effect of the entomopathogen isolates than those of others. The parameters "b" and "c" in the Weibull model for the control group were 31.724 and 8.945 (Table 4). These results point out that the control group M. persicae population fit the increasing type of population (Figure 4).

The most fitted models of the age-related fertility rate $\left(\mathrm{m}_{\mathrm{x}}\right)$ of $M$. persicae individuals exposed to different doses of $B$. bassiana's LD.2016 and M6-4 isolates were determined by the Enkegaard regression model (Figure 5). The given data in Figure 6 are the Enkegaard regression models fitted on the age-related fertility rate $\left(\mathrm{m}_{\mathrm{x}}\right)$ of $M$. persicae individuals used as the control group. As in the Weibull distribution model, determination coefficient $\left(\mathrm{R}^{2}\right)$ and residual sum of squares (RSS) values were used as the criteria of the conformity degree in the Enkegaard regression models (Kontodimas et al. 2004).

The parameters "a" and "b" in the Enkegaard model were found as 5.058 and 0.242 for the individuals exposed to $10^{6}$

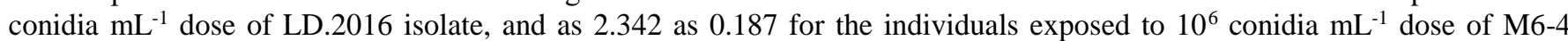
isolate. The parameters " $a$ " and " $b$ " for the individuals exposed to $10^{7}$ conidia $\mathrm{mL}^{-1}$ dose were determined as 2.265 and 0.149 for the LD.2016 isolate-exposed individuals and as 0.840 and 0.087 for the M6-4 isolate-exposed individuals. As for the individuals exposed to $10^{8}$ conidia $\mathrm{mL}^{-1}$ doses of the isolates, the parameters "a" and "b" were computed as 6.280 and 0.437 for LD.2016 isolate-exposed individuals and as 3.172 and 0.280 for M6-4 isolate-exposed individuals. As for in the model belonging to the control group, the parameters "a" and " $b$ " were found as 1.813 and 0.163 , respectively (Table 5).

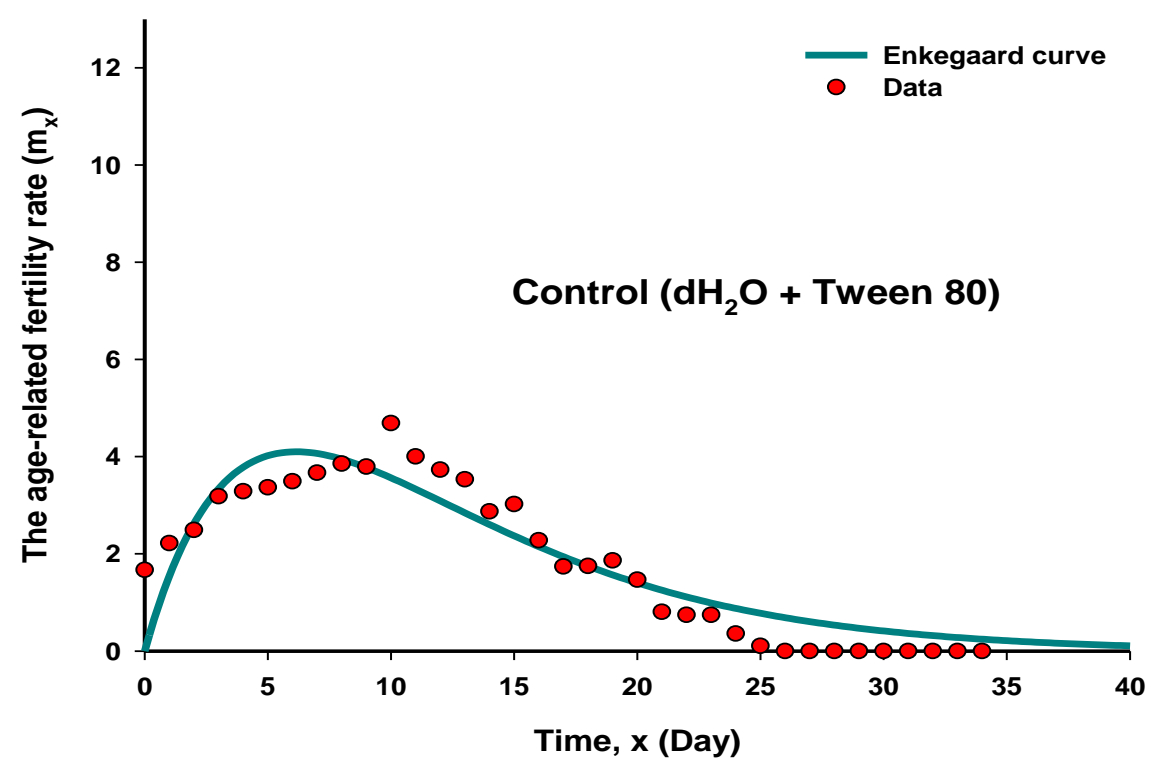

Figure 6- The Enkegaard regression models fitted on the age-related fertility rate $\left(\mathrm{m}_{\mathrm{x}}\right)$ of Myzus persicae individuals used as the control group

Table 5- The parameters of The Enkegaard regression models fitted on the age-related fertility rate $\left(\mathrm{m}_{\mathrm{x}}\right)$ of $M$ Mzus persicae individuals exposed to different doses of Beauveria bassiana's LD.2016 and M6-4 isolates*

\begin{tabular}{|c|c|c|c|c|c|}
\hline & Dose & $a$ & $b$ & $R^{2}$ & $R S S$ \\
\hline \multicolumn{2}{|c|}{ Control } & $1.813 \pm 0.151$ & $0.163 \pm 0.008$ & 0.869 & 10.727 \\
\hline \multirow{3}{*}{ } & $10^{6}$ & $5.058 \pm 0.446$ & $0.242 \pm 0.012$ & 0.904 & 20.798 \\
\hline & $10^{7}$ & $2.265 \pm 0.735$ & $0.149 \pm 0.040$ & 0.474 & 55.687 \\
\hline & $10^{8}$ & $6.280 \pm 1.546$ & $0.437 \pm 0.069$ & 0.783 & 8.299 \\
\hline \multirow{3}{*}{${ }^{\vec{b}}$} & $10^{6}$ & $2.342 \pm 0.227$ & $0.187 \pm 0.011$ & 0.853 & 11.761 \\
\hline & $10^{7}$ & $0.840 \pm 0.315$ & $0.087 \pm 0.038$ & 0.464 & 25.412 \\
\hline & $10^{8}$ & $3.172 \pm 0.784$ & $0.280 \pm 0.042$ & 0.617 & 18.076 \\
\hline
\end{tabular}

*: The model parameters, a, and b, are given with their standard errors $(\mathrm{P}<0.0001)$ 


\section{Conclusions}

The statistical analysis applied to the obtained data demonstrated that net reproductive rate $\left(\mathrm{R}_{0}\right)$, the mean generation time $\left(\mathrm{T}_{0}\right)$, finite rate of increase $(\lambda)$ and gross reproduction rate (GRR) values decreased with increasing concentration. In addition, the Weibull distribution and Enkegaard regression models applied on the age-related survival rate $\left(1_{x}\right)$ and the age-related fertility rate $\left(\mathrm{m}_{\mathrm{x}}\right)$ of B. bassiana's LD.2016 and M6-4 isolates-exposed M. persicae individuals showed compatibility to obtained data. According to these results, it is seen that these entomopathogenic fungus isolates may be used within the scope of the integrated control method to be applied against M. persicae. Entomopathogenic fungi may be a suitable alternative instead of chemicals, since they do not have any toxic effects on mammals (Sevim et al. 2015). Also, a study performed on sub-lethal effect of combination of $M$. anisopliae and imidacloprid on life table of $M$. persicae asserted that the applications made did not have a significant effect on the values of mean generation time $\left(\mathrm{T}_{0}\right)$. Although most sub-lethal dose applications do not have a significant effect on the life table characteristics of $M$. persicae, the method would be a suitable procedure for controlling aphids by increasing the fungal concentration (Rashki et al. 2015). In future studies, it would be beneficial to investigate the effectiveness of these isolates of $B$. bassiana against $M$. persicae under field and greenhouse conditions. In addition to this, another point to be considered is that the determination of the effects of these isolates on wildlife and natural enemies are essential. What has been explained so far showed that B. bassiana's LD.2016 and M6-4 isolates can likely be considered to be involved in biological control practices within the scope of an Integrated Pest Management (IPM) program to be prepared against $M$. persicae.

\section{Acknowledgements}

This study is a part of M.Sc. thesis performed by the first author in the Institute of Graduate Education in Isparta University of Applied Sciences.

\section{References}

Andorno A V \& López S N (2014). Biological control of Myzus persicae (Hemiptera: Aphididae) through banker plant system in protected crops. Biological Control 78: 9-14

Azizoğlu U, Bulut S \& Y1lmaz S (2012). Biological control in organic farming; entomopathogen bioinsecticides. Erciyes University Journal of the Institute of Science and Technology 28(5): 375-381

Baydar R, Güven Ö \& Karaca İ (2016). Occurrence of entomopathogenic fungi in agricultural soils from Isparta Province in Turkey and their pathogenicity to Galleria mellonella (L.) (Lepidoptera: Pyralidae) larvae. Egyptian Journal of Biological Pest Control 26(2): 323-327

Bayındır A, Özger Ş \& Birgücü A K (2016). Effects of Some Plant Extracts on Biology of Myzus persicae. Turkish Journal of Agricultural Research 3: 96-101. Doi: 10.19159/tutad.76219

Birch L C (1948). The intrinsic rate of natural increase of an insect population. Journal of Animal Ecology 17: 15-26

Birgücü A K \& Bayındır-Erol A (2018). Maternal age effect on biology of aphids: a lifetable approaches. Fresenius Environmental Bulletin 11: 7470-7478

Birgücü A K, Özger Ş, Pohl D, Karaca İ (2018). Effects of soil application of neem on some biological characteristics of Myzus persicae (Sulzer) (Hemiptera: Aphididae). Journal of Agricultural Sciences 24: 256-268

Çelebi Ö (2012). Determination of Bacterial Flora and Microbial Control Agents of Eurygaster integriceps (Put.) (Hemiptera: Scutelleridae) Master Thesis, Recep Tayyip Erdoğan University, TUR (Unpublished)

Deevey E S (1947). Life Tables for natural populations of animals. The Quarterly Review of Biology 22(4): 283-314

Demirci F, Muştu M, Kaydan M B \& Ülgentürk S (2011). Laboratory evaluation of the effectiveness of the entomopathogen; Isaria farinosa, on Citrus mealybug, Planococcus citri. Journal of Pest Science 84: 337-342

Enkegaard A (1993). The poinsettia strain of the cotton whitefly, Bemisia tabaci (Hom.; Aleyrodidae): biological and demographic parameters on poinsettia (Euphorbia pulcherrima) in relation to temperature. Bulletin of Entomological Research 83: 535-546

Erdoğan P (2015). Insecticidal effects of extracts of Capsicum annuum L. (Solanaceae and Allium sativum L. (Amaryllidaceae) on Myzus persicae (Sulzer) [(Hemiptera: Aphididae)]. Plant Protection Bulletin 55(4): 305-315

Güven Ö, Baydar R, Temel C \& Karaca İ (2014). The effects of some entomopathogenic fungi against Aphis fabae (Scopoli) (Hemiptera: Aphididae). Turkish Journal of Biological Control 5(2): 149-158

Hansen D L, Brødsgaard H F \& Enkegaard A (1999). Life table characteristics of Macrolophus caliginosus preying upon Tetranychus urticae. Entomologia Experimentalis et Applicata 93: 269-275

Huang Y B \& Chi H (2012). Assessing the application of the jackknife and bootstrap techniques to the estimation of the variability of the net reproductive rate and gross reproductive rate: a case study in Bactrocera cucurbitae (Coquillett) (Diptera: Tephritidae). Journal of Agriculture and Forest Entomology 61(1): 37-45

İnanlı C, Yoldaş Z \& Birgücü A K (2012). Effects of entomopathogenic fungi, Beauveria bassiana (Bals.) and Metarhizium anisopliae (Metsch.) on larvae and egg stages of Tuta absoluta (Meyrick) (Lepidoptera: Gelechiidae). Journal of Agriculture Faculty of Ege University 49(3): 239-242

Kairo M T K \& Murphy S T (1995). The life history of Rodolia iceryae Janson (Coleoptera: Coccinellidae) and the potential for use in innoculative releases against Icerya pattersoni Newstead (Homoptera: Margarodidae) on coffee. Journal of Applied Entomology 119: 487-491

Khatri D, He X Z, Wang Q (2017). Effective biological control depends on life history strategies of both parasitoid and its host: evidence from Aphidius colemani-Myzus persicae system. Journal of Economic Entomology 110(2): 400-406

Kontodimas D C, Eliopoulos P A, Stathas G J \& Economou L P (2004). Comparative temperature-dependent development of Nephus includens (kirsch) and Nephus bisignatus (boheman) (Coleoptera: Coccinellidae), preying on Planococcus citri (risso) (Homoptera: Pseudococcidae): Evaluation of a linear and various non-linear models using specific criteria. Environmental Entomology 33: 1-11 
La Rossa F R, Vasicek A \& Lopez M C (2013). Effects of pepper (Capsicum annuum) cultivars on the biology and life table parameters of Myzus persicae (Sulz.) (Hemiptera: Aphididae). Neotropical Entomology 42: 634-641

Lawo J P \& Lawo N C (2011). Misconceptions about the comparison of intrinsic rates of natural increase. Journal of Applied Entomology 135: 715-725

Meyer J S, Ingersoll C G, McDonald L L \& Boyce M S (1986). Estimating uncertainty in population growth rates: Jackknife vs. Bootstrap techniques. Ecology 67: 1156-1166

Özçelik N, Bal G, Demirci F \& Muştu M (2013). Effects of Isaria farinosa and Purpureocillium lilacinum on green peach aphid Myzus persicae (Sulzer) (Hemiptera: Aphididae). Turkish Journal of Biological Control 4(1): 23-29

Pinder J E, Wiener J G \& Smith M H (1978). The Weibull distribution: a new method of sumarizing survivorship data. Ecology 59: 175-179

Rashki M \& Shirvani A (2013). The effect of entomopathogenic fungus, Beauveria bassiana on life table parameters and behavioural response of Aphis gossypii. Bulletin of Insectology 66(1): 85-91

Rashki M, Talepour F \& Shirvani A (2015). Sub-lethal effect of combination of Metarhizium anisopliae and imidacloprid on life table of Myzus persicae (Hem.: Aphididae). Journal of Crop Protection 4(4): 577-587

Rath A C (2000). The use of entomopathogenic fungi for control of termites. Biocontrol Science and Technology 10: 563-581

Ricci M, La Rossa F R \& Vasicek A (2000). Demografía del “pulgón verde del duraznero" Myzus persicae (Sulzer) (Homoptera: Aphidoidea) sobre pimiento (Capsicum annuum) en condiciones de laboratorio. Revista Ceiba Honduras 41(1): 17-20

Sevim A, Sevim E \& Demirbağ Z (2015). General biology of entomopathogenic fungi and their potential to control pest species in Turkey. Erzincan University Journal of Science and Technology 8(1): 115-147

Tingle C C D \& Copland M J W (1989). Progeny production and adult longevity of the mealybug parasitoids Anagyrus pseudococci, Leptomastix dactylopii and Leptomastidea abnormis (Hymenoptera: Encyrtidae) in relation to temperature. Entomophaga 34: 111-120

Tukey J W (1949). Comparing individual means in the analyses of variance. Biometrics 5: 99-114

Uzuner S, Güner B G, Ayar Ö \& Yaman M (2017). The effects of entomopathogenes used in biological control on bees. Bee Studies 9(1): 919

Velioğlu A S \& Toros S (2002). Insecticide resistance in populations of Myzus persicae (Sulz.) (Hom.: Aphididae) from different regions of Turkey against some insecticides. Plant Protection Bulletin 42(1-4): 67-79

Wang J J, Tsai J H, Zhao Z M \& Li L S (2000). Development and reproduction of the psocid Liposcelis bostrychophila (Psocoptera: Liposcelididae) as a function of temperature. Annals of the Entomological Society of America 93: 261-270

Yu J Z, Chi H \& Chen B H (2013a). Comparison of the life tables and predation rates of Harmonia dimidiata (F.) (Coleoptera: Coccinellidae) fed on Aphis gossypii Glover (Hemiptera: Aphididae) at different temperatures. Biological Control 64: 1-9

Yu L Y, Chen Z Z, Zheng F Q, Shi A J, Guo T T, Yeh B H, Chi H \& Xu Y Y (2013b). Demographic analysis, a comparison of the jackknife and bootstrap methods, and predation projection: A Case Study of Chrysopa pallens (Neuroptera: Chrysopidae). Journal of Economic Entomology 106(1): 1-9

Zimmermann G (2007). Review on safety of the entomopathogenic fungi Beauveria bassiana and Beauveria brongniartii. Biocontrol Science and Technology 17: 553-596

(C) 2022 by the author(s). Published by Ankara University, Faculty of Agriculture, Ankara, Turkey. This is an Open Access article distributed under the terms and conditions of the Creative Commons Attribution (CC BY) license (http://creativecommons.org/licenses/by/4.0/), which permits unrestricted use, distribution, and reproduction in any medium, provided the original work is properly cited. 